\title{
BMJ Open Ethnic differences in body mass index trajectories from 18 years to postpartum in a population-based cohort of pregnant women in Norway
}

\author{
Tarja I Kinnunen, ${ }^{1}$ Kåre R Richardsen, ${ }^{2}$ Line Sletner, ${ }^{3}$ Leila Torgersen, ${ }^{4}$ \\ Christine Sommer, ${ }^{5}$ Christin W Waage, ${ }^{6}$ Ibrahimu Mdala, ${ }^{7}$ Anne Karen Jenum ${ }^{7}$
}

To cite: Kinnunen TI, Richardsen KR, Sletner L, et al. Ethnic differences in body mass index trajectories from 18 years to postpartum in a populationbased cohort of pregnant women in Norway. BMJ Open 2019;9:e022640. doi:10.1136/ bmjopen-2018-022640

\section{- Prepublication history for} this paper is available online. To view these files, please visit the journal online (http://dx.doi org/10.1136/bmjopen-2018022640).

Received 5 March 2018 Revised 20 November 2018 Accepted 28 November 2018

Check for updates

(c) Author(s) (or their employer(s)) 2019. Re-use permitted under CC BY-NC. No commercial re-use. See rights and permissions. Published by BMJ.

For numbered affiliations see end of article.

Correspondence to

Dr Anne Karen Jenum;

a.k.jenum@medisin.uio.no

\section{ABSTRACT}

Objectives To explore ethnic differences in changes in body mass index (BMI) from the age of 18 years to 3 months postpartum.

Design A population-based cohort study.

Setting Child Health Clinics in Oslo, Norway.

Participants Participants were 811 pregnant women (mean age 30 years). Ethnicity was categorised into six groups.

Primary outcome measures The outcome variable was BMI $\left(\mathrm{kg} / \mathrm{m}^{2}\right)$ measured at the age of 18 and 25 years, at prepregnancy and at 3 months postpartum. Body weight at 18 years, 25 years and prepregnancy were self-reported in early pregnancy, while body height and weight at 3 months postpartum were measured. The main statistical method was generalised estimating equations, adjusted for age. The analyses were stratified by parity due to ethnicity $\times$ time $\times$ parity interaction $(p<0.001)$.

Results Primiparous South Asian women had a 1.45 (95\% $\mathrm{Cl} 0.39$ to 2.52$) \mathrm{kg} / \mathrm{m}^{2}$ higher and Middle Eastern women had 1.43 (0.16 to 2.70) $\mathrm{kg} / \mathrm{m}^{2}$ higher mean BMI increase from 18 years to postpartum than Western European women. Among multiparous women, the mean BMI increased 1.99 (1.02 to 2.95) kg/m² more in South Asian women, 1.48 (0.31 to 2.64) $\mathrm{kg} / \mathrm{m}^{2}$ more in Middle Eastern women and 2.49 (0.55 to 4.42) $\mathrm{kg} / \mathrm{m}^{2}$ more in African women than in Western European women from 18 years to prepregnancy. From 18 years to postpartum, the mean increase was 4.40 (2.38 to 6.42) $\mathrm{kg} / \mathrm{m}^{2}$ higher in African women and 1.94 to $2.78 \mathrm{~kg} / \mathrm{m}^{2}$ higher in the other groups than in Western European women.

Conclusions Multiparous women of ethnic minority origin seem substantially more prone to long-term weight gain than multiparous Western European women in Norway.

\section{INTRODUCTION}

Overweight and obesity increase the risk for several adverse pregnancy outcomes, including gestational diabetes, pre-eclampsia, preterm delivery, caesarean section, delivery complications, low and high birth weight, and fetal and infant mortality. ${ }^{1-7}$ Many groups of women of ethnic minority or migrant origin are more likely to be overweight or
Strengths and limitations of this study

- This multiethnic population-based cohort study of pregnant women had relatively high participation rates and was representative of pregnant women in the study area.

- To ensure high quality of the data, study questionnaires were available in nine languages and professional interpreters assisted in the interviews when needed.

- The main analyses were adjusted for age as a time-dependent covariate, and the additional analyses among multiparous women were adjusted also for parity.

- The main limitation is that body weight data at the age of 18 and 25 years were retrospectively self-reported in early pregnancy.

- The African, East Asian and Eastern European groups had quite a small number of participants.

obese $^{6-11}$ and have higher risk of gestational diabetes and other adverse maternal and fetal outcomes $^{12-14}$ than women in the majority population in Western countries. The risk of type 2 diabetes and cardiovascular diseases are also increased in many migrant and ethnic minority populations. ${ }^{15-18}$

Higher parity has been associated with slightly higher mean body mass index (BMI) in women in different countries ${ }^{19} 20$ which can be partly explained by postpartum weight retention. We have previously reported that some ethnic minority groups gain more weight during pregnancy ${ }^{21}$ or retain more weight postpartum on average ${ }^{22}$ compared with Western European women which might partly explain ethnic differences observed in the prevalence of overweight and obesity in the general adult female population.

On the other hand, some migrant groups have higher BMI already in childhood or adolescence ${ }^{23-25}$ which may persist until adulthood. Most previous studies have compared 
BMI between ethnic groups cross-sectionally, ${ }^{8-11} 26$ and no longitudinal comparisons are available from Europe. Studies conducted in the USA have shown that black women had a higher baseline weight and also gained more weight than white US women during a 16-year follow-up ${ }^{27} 28$ and a 34 -year follow-up. ${ }^{29}$ Low socioeconomic status, both in early life and later in life, may be independent risk factors for obesity in adulthood. ${ }^{2729-31}$

Longitudinal studies of BMI in multiethnic populations are required to detect whether ethnic minority women are at higher risk for long-term weight gain. This will help to plan timely interventions to prevent weight gain that may increase the risk of non-communicable diseases. The aim of this study was to model the change in women's BMI from the age of 18 years to 3 months postpartum by ethnicity in a population-based cohort of pregnant women (mean age of 30 years).

\section{MATERIALS AND METHODS}

\section{Study design and population}

The present study used data from a population-based cohort study consisting of pregnant women who attended antenatal care at Child Health Clinics in three city districts of Oslo, Norway. ${ }^{32}$ In these districts, approximately $60 \%$ of newborns were of non-Western ethnic origin and $75 \%-85 \%$ of pregnant women used antenatal care at these clinics at the time of the study. To fulfil the inclusion criteria for the study, pregnant women had to live in one of three city districts in Groruddalen, plan to give birth at one of the two study hospitals, be at $\leq 20$ weeks' gestation, be able to communicate in Norwegian or any of the eight languages to which all the information materials and questionnaires were translated (Arabic, English, Sorani, Somali, Tamil, Turkish, Urdu and Vietnamese), and be able to give informed written consent. Exclusion criteria were prepregnancy diabetes or other chronic diseases requiring intensive hospital follow-up during pregnancy (eg, known pregnancy complications or severe psychiatric conditions), or if they had participated in the same study during a previous pregnancy lasting $\geq 22$ weeks.

A total of 823 women were enrolled at 15 weeks' gestation on average between May 2008 and May 2010. The overall participation rate was $74 \%$ among the eligible women, but it varied across ethnic groups (Western European $82 \%$, Eastern European 75\%, South Asian 73\%, Middle Eastern 65\%, African 64\% and East Asian 63\%). Women from South and Central America were excluded from the analyses due to a small number $(n=12)$. The final sample size was therefore 811 .

\section{Patient involvement}

Our participants were healthy pregnant women. They were not involved in the design of the study. The results of the study will be disseminated to the participants via STORK Groruddalen study website.

\section{Data collection}

The data were collected by trained, certified study midwives who interviewed the participants, filled in the questionnaires and obtained the objective measures at the Child Health Clinics at inclusion (mean 15 weeks' gestation) and approximately 3 months postpartum. ${ }^{32}$ Whenever a participant was not fluent in Norwegian, professional interpreters assisted during the interviews, using the translated versions of the questionnaires, to ensure consistency in translations.

\section{Outcome variables}

The main outcome of the present study was BMI $(\mathrm{kg} /$ $\mathrm{m}^{2}$ ) measured at the age of 18 and 25 years, at prepregnancy (mean age 30 years at inclusion) and at 3 months postpartum. Body height was measured to the nearest $0.1 \mathrm{~cm}$ using a fixed stadiometer at inclusion. At the same visit, the participants recalled their weight at the age of 18 and 25 years (if older than 25 years) and at prepregnancy. At 3 months postpartum, Tanita-weight BC-418 MA (Tanita, Tokyo, Japan) was used to measure weight in light clothing without shoes in a fasting state.

\section{Ethnicity and other background variables}

The participants provided information on ethnicity and other background variables at inclusion. Ethnicity was defined by the participant's country of birth or mother's country of birth if the mother was born outside Europe or North America. This definition recognises both the biological and cultural aspects of the 'second generation of migrants' and the importance of the maternal line in transferring cultural, language and dietary habits to their children, and is commonly used in epidemiological research on ethnic minorities with migrant background.$^{33}$ Ethnicity was categorised into six broad groups: Western Europe (including North America), Eastern Europe, Middle East (including North Africa and Central Asia), Africa (except for North Africa), South Asia and East Asia. Western European women were used as the reference group (94\% born in Norway). Age was used as a continuous time-dependent variable: age is 18 years for time 1, 25 years for time 2, age at inclusion for time 3 and age at inclusion plus 1 year for time 4 . Parity was dichotomised to 1 (primiparous, ie, the present delivery was the first) and $\geq 2$ (multiparous). Duration of residence in Norway was dichotomised to $<2$ years (recent migrants) or $\geq 2$ years among women who were not born in Norway.

The construction of the current and the early life socioeconomic status scores has been described previously in detail. ${ }^{34}$ Briefly, a principal component analysis was used to construct each socioeconomic status score component. The final component for current socioeconomic status was dominated by five variables: occupation, educational level, tenure (owning vs renting), level of household crowding (persons in household per room) and employment status (not paid work vs paid work outside of home), and named 'socioeconomic status score'. The mean (SD) socioeconomic status score was $0(1)$, with values ranging 
from -2.9 (lowest position) to 2.6 (highest position). The variables used to construct the early life socioeconomic status score were family occupational class (highest of mother or father), rooms per person in household and family ownership of car when the participant was 10 years old.

\section{Statistical methods}

The percentage of missing data was $19.7 \%$ for postpartum BMI due to loss to follow-up, but only $3.8 \%$ for BMI at the age of 18 years or 25 years, $1.5 \%$ for prepregnancy BMI and $0.5 \%$ for socioeconomic status score. The missing data were imputed using multiple imputation. ${ }^{35}$ We used fully conditional specification, an iterative Markov Chain Monte Carlo method to impute the data by running 50 imputations. Patterns of missing data were first analysed to inform the imputation model. The missing data were assumed to be missing completely at random. The following variables were associated with higher odds for having missing data for at least one of the BMI variables: ethnicity, age at inclusion, parity, weeks' gestation at enrolment, current socioeconomic score and socioeconomic score in early life. All these variables were used to impute missing data in the same variables in the dataset. For women under 25 years of age at inclusion, BMI at the age of 25 years was set missing by default. Results based on the pooled data of 50 imputations are reported. The imputed data analyses are reported as the primary analyses and the complete data analyses as secondary analyses.

The descriptive results are presented as means and SD or as numbers and percentages. Cross-sectional analysis of covariance was first used to examine ethnic differences in mean BMI, adjusted for age at inclusion, at each of the four time points and by parity. As the pooled analyses did not give $p$ values or $95 \%$ CIs for differences in means between Western European women and the other groups, statistical significance of the differences was assessed based on $95 \%$ CIs of the means of each group, non-overlapping CIs indicating a statistically significant difference between the comparison groups. Next, linear generalised estimating equations (GEE) were fitted to explore ethnic differences in changes in mean BMI from 18 years of age until 3 months postpartum. The independent correlation structure, which had the smallest quasi-likelihood independence criterion in preliminary analyses, was used. The main model included BMI at the four time points (18 years, 25 years, prepregnancy and 3 months postpartum), ethnicity, time (values 1 to 4 ), the interaction term ethnicity $\times$ time, and was adjusted for age as a time-dependent covariate. The secondary models were additionally adjusted for either current or early life socioeconomic status score, as these variables were associated with BMI and varied by ethnicity in our data. A statistically significant interaction $(\mathrm{p}<0.001)$ was observed for ethnicity $\times$ timexparity in preliminary analyses, suggesting that parity modifies ethnic differences in BMI change. Therefore, the analyses were stratified by parity (primiparous vs multiparous). The role of multiparity was explored in more detail by restricting the analysis to multiparous women and adjusting the GEE model for age as a time-dependent covariate and parity as a continuous variable. The results of the GEE models are presented as regression coefficients $(\beta)$ with $95 \%$ CI. The data were analysed using the SPSS statistical software package V.23.0.

\section{RESULTS}

\section{Characteristics of the participants}

Table 1 shows the participant characteristics. The mean age at inclusion ranged from 28 to 31 years across ethnic groups. The mean socioeconomic status score was higher among Western European women than in the other ethnic groups. The percentages of women with $\geq 2$ previous deliveries were highest among African, Middle Eastern and South Asian women. Western and Eastern European women were tallest and East Asian women were shortest on average. The percentage of women born in Norway was $89 \%$ among Western European women and varied from $2 \%$ to $21 \%$ across the other ethnic groups. Of women not born in Norway, the percentage of recent migrants (<2 years in Norway) varied from $11 \%$ to $23 \%$ across ethnic groups.

\section{Cross-sectional comparisons of the mean BMI by ethnicity at} each time point

The mean age-adjusted BMI is illustrated by ethnicity at each time point, separately for primiparous and multiparous women in figure 1A,B. Among primiparous women, the Western European reference group had a mean BMI of $22.1 \mathrm{~kg} / \mathrm{m}^{2}$ at the age of 18 years. South Asian women had a lower mean BMI than the reference group at 18 years and 25 years of age and East Asian women at prepregnancy. Other than that, none of the ethnic groups differed statistically significantly from the reference group at any of the four time points. Among multiparous women, the mean BMI was $21.8 \mathrm{~kg} / \mathrm{m}^{2}$ at the age of 18 years in the reference group. South Asian and East Asian women had a lower mean BMI at 18 years of age and East Asian women also at 25 years of age compared with the reference group. On the other hand, Middle Eastern multiparous women had a higher mean BMI at 25 years of age, prepregnancy and 3 months postpartum, and African women had a higher mean BMI at prepregnancy and 3 months postpartum than the multiparous reference group. The results were similar in the complete data, except that the differences were not statistically significant for primiparous East Asian women and for multiparous African women at prepregnancy (data not shown).

\section{Longitudinal comparison of changes in the mean BMI by ethnicity}

Figure 2A,B show differences in changes in the mean BMI from the age of 18 years to prepregnancy and to 3 months postpartum in each ethnic minority group compared with Western European women, adjusted for age. The 


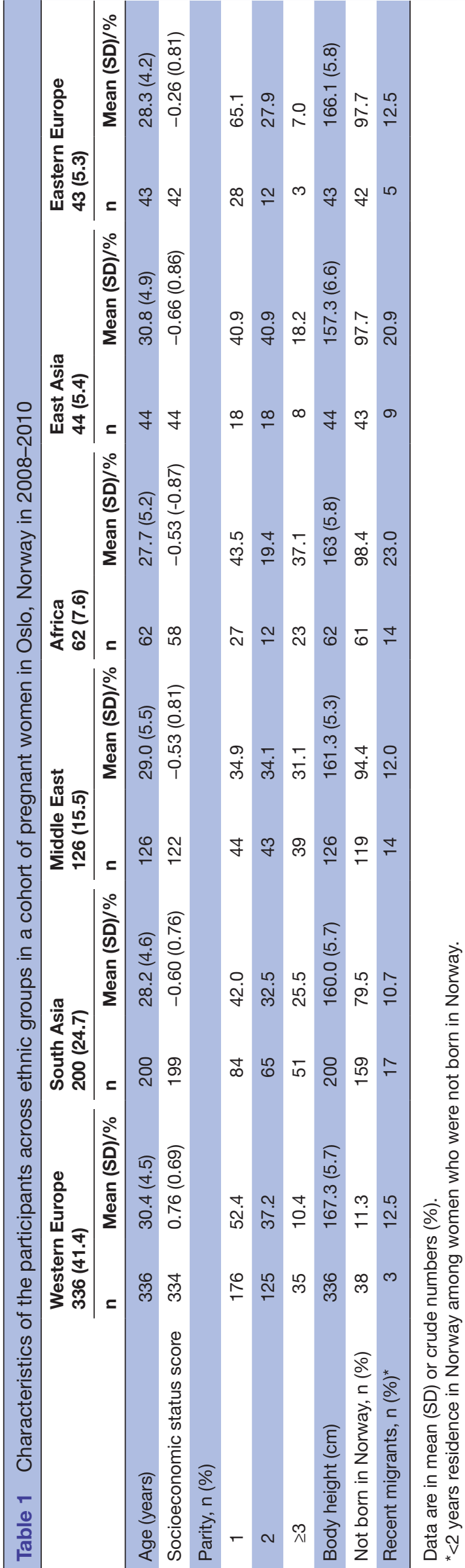

following differences were statistically significant based on the $95 \%$ CIs. Concerning primiparous women, the BMI change from 18 years to postpartum was $1.45 \mathrm{~kg} / \mathrm{m}^{2}$ higher in South Asian women $(\mathrm{p}=0.008)$ and $1.43 \mathrm{~kg} / \mathrm{m}^{2}$ higher in Middle Eastern women $(p=0.027)$ compared with the reference group. Among multiparous women, the mean increase in BMI by prepregnancy was $1.99 \mathrm{~kg} /$ $\mathrm{m}^{2}$ higher in South Asian women $(\mathrm{p}<0.001), 1.48 \mathrm{~kg} / \mathrm{m}^{2}$ higher in Middle Eastern women $(\mathrm{p}=0.013)$ and $2.49 \mathrm{~kg} /$ $\mathrm{m}^{2}$ higher in African women $(\mathrm{p}=0.012)$ than in the reference group. By postpartum, the mean BMI had increased by $4.40 \mathrm{~kg} / \mathrm{m}^{2}$ more in African women $(\mathrm{p}<0.001)$ and $1.94-2.78 \mathrm{~kg} / \mathrm{m}^{2}$ more in the other ethnic minority groups $(\mathrm{p}=0.011$ to $<0.001)$ compared with the reference group.

The secondary analysis based on the complete data yielded mainly similar results as the primary analysis, although there were a few minor differences in the statistical significance of the results (figure $3 \mathrm{~A}, \mathrm{~B}$ ). The coefficients were generally very similar to those based on the imputed data.

When restricting the analysis to the multiparous women and adjusting for age and parity (as a continuous variable) in the GEE model with imputed values, the results were practically the same (data not shown) as the results observed among multiparous women when adjusting for age only (figure 2B). When the GEE model was adjusted for age and current socioeconomic status or age and early life socioeconomic status, the results were very similar to those adjusted for age only both among primiparous and multiparous women (data not shown).

\section{DISCUSSION}

To our knowledge, this is the first study to explore ethnic differences in long-term BMI trajectories among women living in a European country. Our main finding was that ethnic differences in long-term weight development differed by parity in this multiethnic cohort of pregnant women. The mean changes in BMI were mainly similar across ethnic groups for primiparous women. In contrast, among multiparous women the mean BMI increase was higher between age 18 up until the current pregnancy in African, South Asian and Middle Eastern women than in Western European women. Further, in multiparous women, BMI increased more from 18 years to postpartum in all ethnic minority groups, compared with Western European women, most pronounced in African women. Results based on the complete data were essentially similar.

Our study has several strengths. We used data from a multi-ethnic population-based cohort study of pregnant women which had relatively high participation rates in each ethnic group $(63 \%-82 \%)$ and was representative of pregnant women attending child health clinics in the study districts. ${ }^{32}$ The study questionnaires were available in nine different languages and professional interpreters were used when needed. Multiple imputation supported 

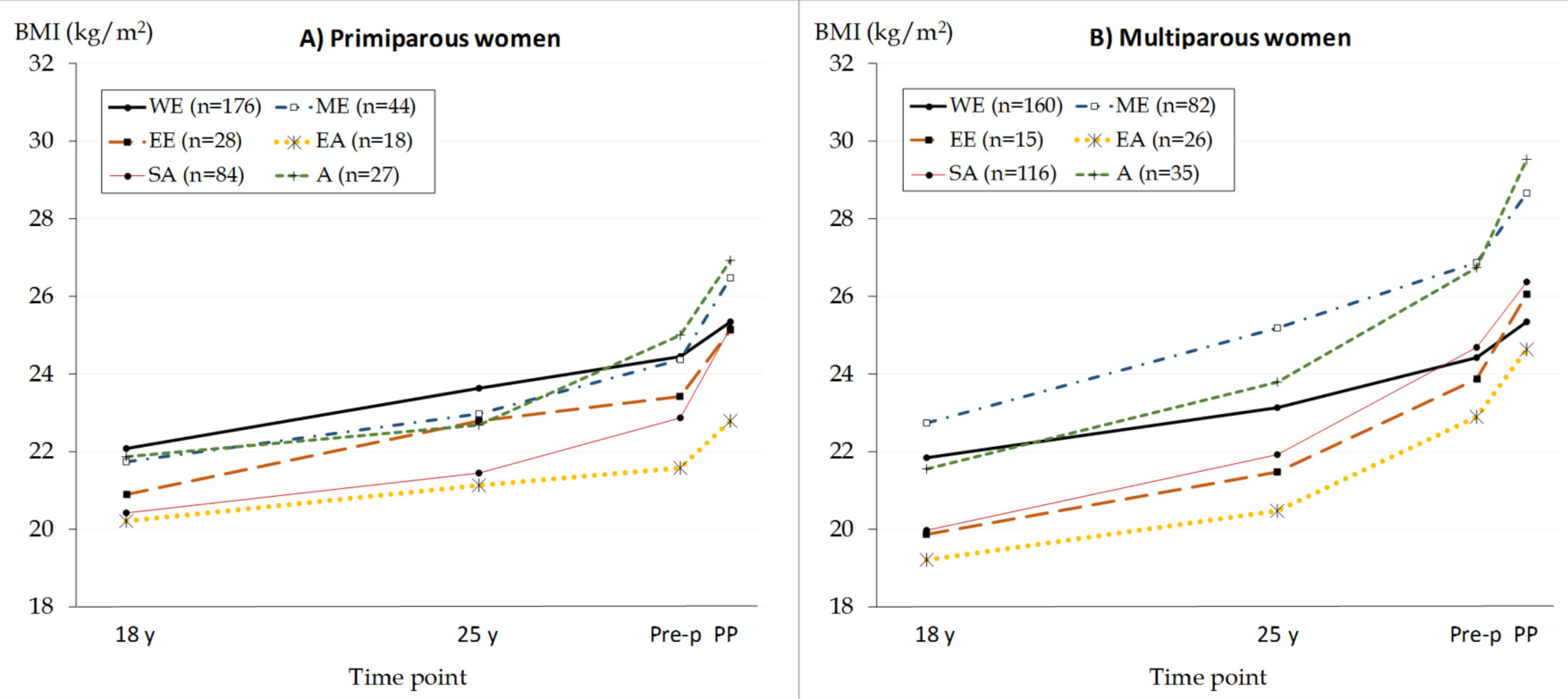

Figure 1 Missing data imputed: mean $\mathrm{BMI}\left(\mathrm{kg} / \mathrm{m}^{2}\right)$ from 18 years to 3 months postpartum across ethnic groups among primiparous (A) and multiparous women (B), based on analysis of covariance adjusted for age. Arrows indicate statistically significant differences compared with WE. A, Africans; BMI, body mass index; EA, East Asians; EE, East Europeans; ME, Middle Easterners; Pre-p, pre-pregnancy; PP, postpartum; SA, South Asians; WE, Western Europeans.

the plausibility of the missing completely at random assumption. The result for multiparous women were also adjusted for parity in additional analyses.

The main limitation of the study is possible misclassification of body weight at the age of 18 and 25 years and prepregnancy, which were retrospectively self-reported. Prepregnancy weight may have been recalled more accurately as it was reported immediately after measuring body weight at the first visit during pregnancy and it correlated very strongly with the measured weight $(\mathrm{r}=0.95-0.97$ in all ethnic groups).${ }^{21}$ However, a review on the validity of self-reported prepregnancy weight ${ }^{36}$ reported that black women had higher reporting errors than white women in the USA, although this is not generalisable to the ethnic minority groups in Norway. Furthermore, there may be ethnic differences in the validity of self-reported body weight at 18 and 25 years of age. We are not aware of any study assessing ethnic differences in the validity of body weight data that is self-reported several years retrospectively. On the other hand, our results on ethnic differences in BMI at different ages are in line with other studies from Norway (see the next paragraph), underpinning the validity of our data. Nevertheless, if under-reporting of earlier body weight was more common among groups that had highest mean BMI (multiparous African and Middle Eastern women), our estimates of ethnic differences in long-term changes in BMI would have been slightly overestimated and the cross-sectional differences in the earlier time points would have been slightly underestimated. Another possible limitation is that we were not able to use socioeconomic status as a time-dependent covariate in the analyses. Additionally, the numbers of women were rather small in the African, East Asian and Eastern European groups, which made it more difficult to observe statistically significant differences between these groups and the Western European reference group.

There are no comparable longitudinal European studies available, but the results of our study can be compared with previous cross-sectional studies in different age groups. An earlier study from Oslo reported that adolescent girls aged 15-16years of Middle Eastern, Eastern European or Western (excluding Norway) origin had slightly higher mean BMI than peers of African, South Asian or East Asian origin, based on self-reported body weight and height. ${ }^{37}$ These findings are essentially similar to our findings on BMI at the age of 18 years, except for African and Eastern European girls. Our findings are mainly in accordance with a cross-sectional population-based study on migrants living in Oslo, when comparing BMI of women in the age group 31-35 years $^{38}$ to the prepregnancy BMI of the multiparous women in our study. Our findings are also in line with a Finnish cross-sectional study including migrant women aged $18-45$ years. ${ }^{11}$ The other cross-sectional European studies did not report mean BMI or prevalence of overweight or obesity separately for women in reproductive age ${ }^{8-10}$ Comparable results have been reported also from studies including older women than in our study. Rabanal $e t a l^{39}$ studied women aged 40-65 years from 11 regions in Norway and found that women of African, Middle Eastern and South Asian origin had clearly higher mean BMI and women of East Asian and South-East Asian origin had lower mean BMI than Norwegian women. Kumar $e t a l^{38}$ reported similar results among women aged 41-60 years who were originally from these regions and living in Oslo. The Finnish cross-sectional study reported a higher 


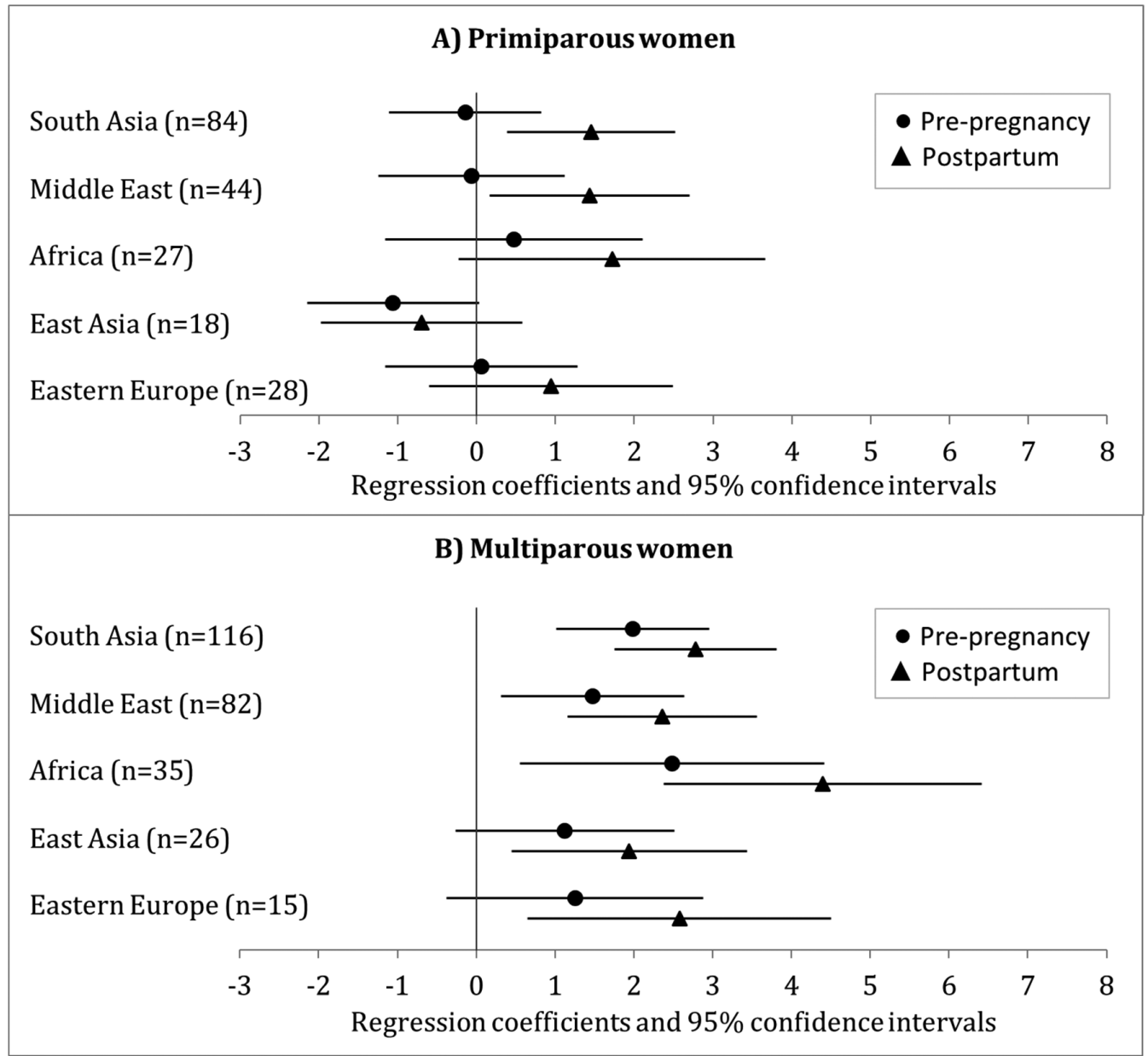

Figure 2 Missing data imputed: changes in the mean body mass index $\left(\mathrm{kg} / \mathrm{m}^{2}\right)$ from the age of 18 years to prepregnancy and to 3 months postpartum in each ethnic minority group compared with Western European women among primiparous (A) and multiparous women (B), regression coefficients and $95 \%$ Cls based on generalised estimating equations adjusted for age.

mean BMI among women aged 30-64 years of Somali and Kurdish origin compared with Finnish women. ${ }^{40}$

Interestingly, adjustment for the number of previous deliveries did not change the observed ethnic differences among multiparous women in our study. This suggests that the observed ethnic differences in BMI change in multiparous women were not a consequence of the larger proportion of women with several children among some ethnic minority groups than among Western European women. However, the numbers of women with at least three previous deliveries were small in some ethnic groups, limiting our power to assess this in detail. Our earlier findings from the same cohort showed that Middle Eastern women had higher gestational weight gain $^{21}$ and Middle Eastern, South Asian and African women had higher postpartum weight retention ${ }^{22}$ than Western European women. As these groups had higher longterm increase in BMI in the present study, they may have gained and retained more weight also during and after their previous pregnancies compared with Western European women. It is important to keep in mind that body fat percentage varies at a given BMI or waist circumference level between ethnic groups. ${ }^{41} 42$ Hence, the relatively large BMI increase in South Asian women may be of particular concern, considering that Asians seem to have higher risk for overweight related health problems at a lower BMI or waist circumference level than other ethnic groups. $^{4142}$

The results of our study and the other studies highlight the importance of paying more attention to factors facilitating or hindering weight management especially among women of African, South Asian or Middle Eastern origin. Pregnancies and postpartum periods may be the most susceptible periods for excessive weight gain especially in these ethnic groups. In our cohort, South Asian women were physically less active in pregnancy ${ }^{43}$ and South Asian and Middle Eastern women were less active postpartum $^{44}$ compared with Western European women. All ethnic minority groups were more likely to have unhealthier dietary pattern in pregnancy than European women, although the differences were largely explained by lower socioeconomic status and lower integration level in ethnic minority groups. ${ }^{45}$ South Asian women were also less likely to breast feed at 3 months postpartum than Western European women 


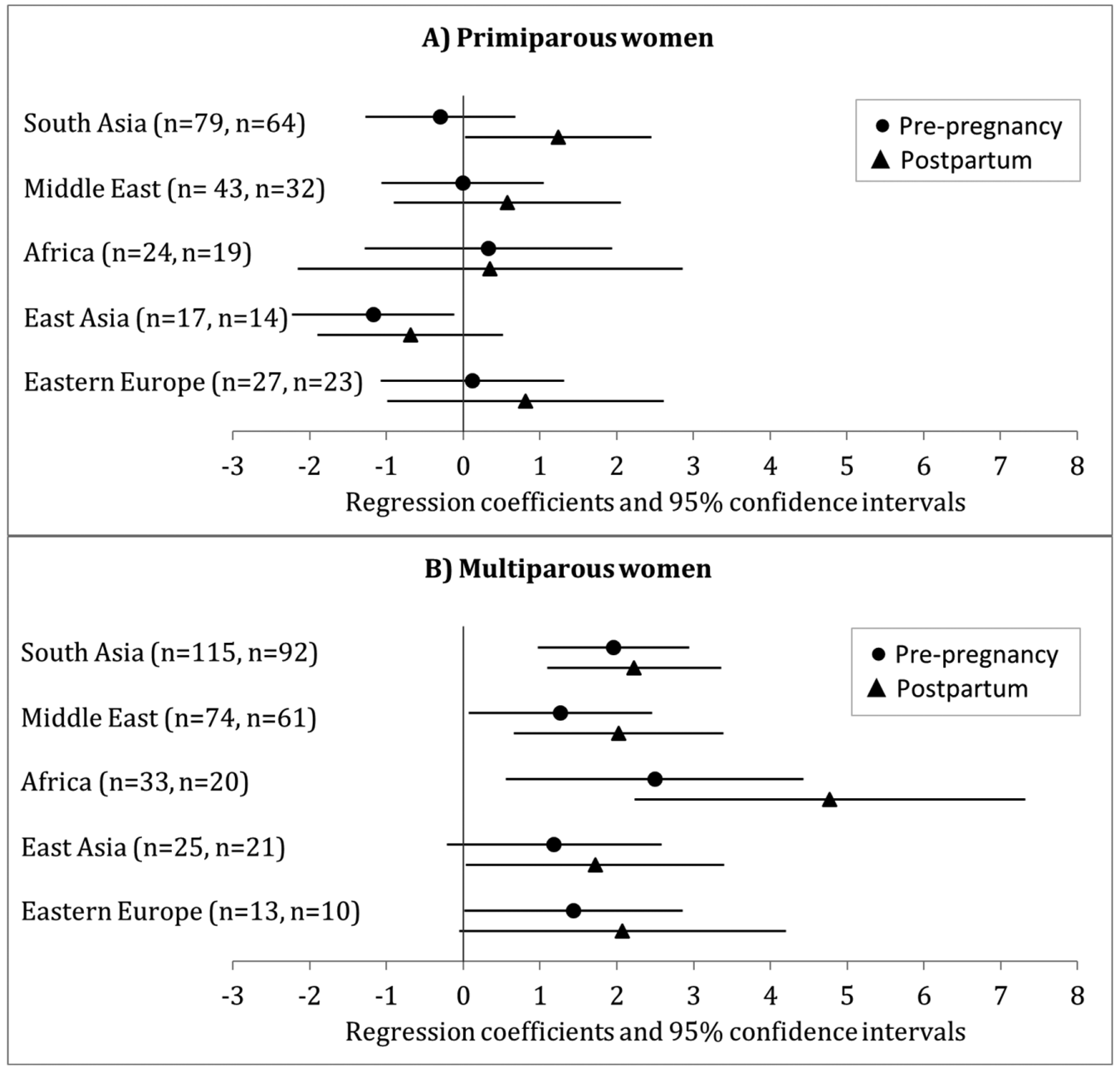

Figure 3 Complete data: changes in the mean body mass index $\left(\mathrm{kg} / \mathrm{m}^{2}\right)$ from the age of 18 years to prepregnancy and to 3 months postpartum in each ethnic minority group compared with Western European women among primiparous (A) and multiparous women $(B)$, regression coefficients and $95 \%$ Cls based on generalised estimating equations adjusted for age. The numbers of women refer to the prepregnancy and the postpartum analyses, respectively.

which may partly explain differences in weight retention. ${ }^{46}$ Furthermore, these findings from our cohort are supported by results from other studies conducted among ethnic minorities in Oslo. Adolescents from ethnic minority groups were more likely to be sedentary and to eat more sweets and soft drinks than adolescents of Western background, although adolescents of Middle Eastern background were more likely to have a higher intake of fruit and vegetables than others. ${ }^{37}$ Therefore, it is important to promote healthy lifestyle from childhood and adolescence as well as during pregnancy and postpartum periods. A qualitative study from Oslo found that recently migrated women of South Asian, African and Middle Eastern origin found it difficult to adjust to the new food culture, and their diet became more restricted after migration. ${ }^{47}$ The researchers recommended that migrants need guidance on how to purchase and prepare healthy food that does not contradict with their own culture, and this should take place in the early phase after migration. A culturally adapted lifestyle intervention study succeeded in reducing risk factors for type 2 diabetes and metabolic syndrome in Pakistani migrant women living in Oslo. ${ }^{48}$

\section{CONCLUSIONS}

In a multiethnic population in Norway, ethnic differences in long-term BMI trajectories in women seem to widen after the first pregnancy. Few ethnic differences were observed in weight development among women who were expecting their first child. However, multiparous women in all ethnic minority groups gained more weight from the age of 18 years until 3 months after delivery than multiparous Western European women, suggesting that pregnancies and postpartum periods may be the most susceptible periods for excessive weight gain in these groups. Adjustment for the number of previous pregnancies did not change the results. The results of the study could be generalised to other women in these ethnic groups living in Norway and possibly also in other European countries with the same migrant groups. Future studies and interventions are needed to promote healthy diet and physical 
activity and find tools for successful weight management among young women from ethnic minority groups.

\section{Author affiliations}

${ }^{1}$ Unit of Health Sciences, Faculty of Social Sciences, Tampere University, Tampere, Finland

${ }^{2}$ Faculty of Health Sciences, Oslo and Akershus University College of Applied Sciences, Oslo, Norway

${ }^{3}$ Department of Child and Adolescents Medicine, Akershus University Hospital, Lørenskog, Norway

${ }^{4}$ Department of Child Development, Norwegian Institute of Public Health, Oslo, Norway

${ }^{5}$ Department of Endocrinology, Morbid Obesity and Preventive Medicine, 0slo University Hospital, Oslo, Norway

${ }^{6}$ Institute of Health and Society, Department of General Practice, Faculty of Medicine, University of Oslo, Oslo, Norway

${ }^{7}$ General Practice Research Unit (AFE), Department of General Practice, Institute of Health and Society, University of Oslo, Oslo, Norway

Contributors TIK, KRR, LS, LT, CS, CWW, IM and AKJ participated in formulating the research question. AKJ and LS designed and carried out the study. TIK, KRR and IM analysed the data. TIK, KRR, LS, LT, CS, CWW, IM and AKJ participated in writing and revising the article and accepted the final version of it.

Funding The data collection was supported by the Research Council of Norway, the South-Eastern Norway Regional Health Authority, Norwegian Directorate of Health and collaborative partners in The City of Oslo, Stovner, Grorud and Bjerke administrative districts.

Competing interests None declared.

Patient consent for publication Not required.

Ethics approval The study protocol was approved by the Regional Ethics Committee (2007/894) and the Norwegian Data inspectorate.

Provenance and peer review Not commissioned; externally peer reviewed.

Data sharing statement The datasets analysed during the current study may be available from the principal investigator (Anne Karen Jenum) on reasonable request.

Open access This is an open access article distributed in accordance with the Creative Commons Attribution Non Commercial (CC BY-NC 4.0) license, which permits others to distribute, remix, adapt, build upon this work non-commercially, and license their derivative works on different terms, provided the original work is properly cited, appropriate credit is given, any changes made indicated, and the use is non-commercial. See: http://creativecommons.org/licenses/by-nc/4.0/.

\section{REFERENCES}

1. Bhattacharya S, Campbell DM, Liston WA, et al. Effect of Body Mass Index on pregnancy outcomes in nulliparous women delivering singleton babies. BMC Public Health 2007;7:168.

2. Athukorala $\mathrm{C}$, Rumbold $\mathrm{AR}$, Willson $\mathrm{KJ}$, et al. The risk of adverse pregnancy outcomes in women who are overweight or obese. BMC Pregnancy Childbirth 2010;10:56.

3. Mamun AA, Callaway LK, O'Callaghan MJ, et al. Associations of maternal pre-pregnancy obesity and excess pregnancy weight gains with adverse pregnancy outcomes and length of hospital stay. BMC Pregnancy Childbirth 2011;11:62.

4. Aune D, Saugstad OD, Henriksen T, et al. Maternal body mass index and the risk of fetal death, stillbirth, and infant death: a systematic review and meta-analysis. JAMA 2014;311:1536-46.

5. Johansson S, Villamor E, Altman M, et al. Maternal overweight and obesity in early pregnancy and risk of infant mortality: a population based cohort study in Sweden. BMJ 2014;349:g6572.

6. Reiss K, Breckenkamp J, Borde T, et al. Contribution of overweight and obesity to adverse pregnancy outcomes among immigrant and non-immigrant women in Berlin, Germany. Eur $J$ Public Health 2015;25:839-44.

7. Poston L, Caleyachetty R, Cnattingius S, et al. Preconceptional and maternal obesity: epidemiology and health consequences. Lancet Diabetes Endocrinol 2016;4:1025-36.

8. Dijkshoorn H, Ujcic-Voortman JK, Viet L, et al. Ethnic variation in validity of the estimated obesity prevalence using self-reported weight and height measurements. BMC Public Health 2011;11:408.
9. Ujcic-Voortman JK, Bos G, Baan CA, et al. Obesity and body fat distribution: ethnic differences and the role of socio-economic status. Obes Facts 2011;4:53-60.

10. Ujcic-Voortman JK, Baan CA, Seidell JC, et al. Obesity and cardiovascular disease risk among Turkish and Moroccan migrant groups in Europe: a systematic review. Obes Rev 2012;13:2-16.

11. Kinnunen TI, Skogberg N, Härkänen T, et al. Overweight and abdominal obesity in women of childbearing age of Russian, Somali and Kurdish origin and the general Finnish population. J Public Health 2018;40:1-9.

12. Bollini P, Pampallona S, Wanner P, et al. Pregnancy outcome of migrant women and integration policy: a systematic review of the international literature. Soc Sci Med 2009;68:452-61.

13. Gagnon AJ, McDermott S, Rigol-Chachamovich J, et al. International migration and gestational diabetes mellitus: a systematic review of the literature and meta-analysis. Paediatr Perinat Epidemiol 2011;25:575-92.

14. Almeida LM, Caldas J, Ayres-de-Campos D, et al. Maternal healthcare in migrants: a systematic review. Matern Child Health $J$ 2013:17:1346-54.

15. Uitewaal PJ, Manna DR, Bruijnzeels MA, et al. Prevalence of type 2 diabetes mellitus, other cardiovascular risk factors, and cardiovascular disease in Turkish and Moroccan immigrants in North West Europe: a systematic review. Prev Med 2004;39:1068-76.

16. Wändell PE, Carlsson A, Steiner KH. Prevalence of diabetes among immigrants in the Nordic countries. Curr Diabetes Rev 2010;6:126-33.

17. Tran AT, Straand J, Diep LM, et al. Cardiovascular disease by diabetes status in five ethnic minority groups compared to ethnic Norwegians. BMC Public Health 2011;11:554.

18. Jenum AK, Diep LM, Holmboe-Ottesen G, et al. Diabetes susceptibility in ethnic minority groups from Turkey, Vietnam, Sri Lanka and Pakistan compared with Norwegians - the association with adiposity is strongest for ethnic minority women. BMC Public Health 2012;12:150.

19. Gore SA, Brown DM, West DS. The role of postpartum weight retention in obesity among women: a review of the evidence. Ann Behav Med 2003;26:149-59.

20. Lopez-Arana S, Burdorf A, Avendano M. Trends in overweight by educational level in 33 low- and middle-income countries: the role of parity, age at first birth and breastfeeding. Obes Rev 2013;14:806-17.

21. Kinnunen $\mathrm{TI}$, Waage CW, Sommer C, et al. Ethnic differences in gestational weight gain: a population-based cohort study in Norway. Matern Child Health J 2016;20:1485-96.

22. Waage CW, Falk RS, Sommer C, et al. Ethnic differences in postpartum weight retention: a Norwegian cohort study. BJOG 2016;123:699-708.

23. Wikström K, Haikkola L, Laatikainen T. Maahanmuuttajataustaisten nuorten terveys ja hyvinvointi. In: Tutkimus pääkaupunkiseudun somali-ja kurditaustaisista nuorista [Health and well-being of adolescents with immigrant background. Study on adolescents with Somali and Kurdish background in capital city area. 17th edn. Helsinki: National Institute for Health and Welfare, 2014.

24. Gualdi-Russo E, Zaccagni L, Manzon VS, et al. Obesity and physical activity in children of immigrants. Eur J Public Health 2014;24(Suppl 1):40-6.

25. Zhang $Q$, Liu R, Diggs $L A$, et al. Does acculturation affect the dietary intakes and body weight status of children of immigrants in the U.S. and other developed countries? A systematic review. Ethn Health 2017:13:1-21.

26. Kumar BN, Selmer R, Lindman AS, et al. Ethnic differences in SCORE cardiovascular risk in Oslo, Norway. Eur J Cardiovasc Prev Rehabil 2009:16:229-34.

27. Insaf TZ, Shaw BA, Yucel RM, et al. Lifecourse socioeconomic position and 16 year body mass index trajectories: differences by race and sex. Prev Med 2014;67:17-23.

28. Insaf TZ, Shaw BA, Yucel RM, et al. Lifecourse socioeconomic position and racial disparities in BMI Trajectories among black and white women: exploring cohort effects in the Americans changing lives' study. J Racial Ethn Health Disparities 2014;1:309-18.

29. Baltrus PT, Lynch JW, Everson-Rose S, et al. Race/ethnicity, life-course socioeconomic position, and body weight trajectories over 34 years: the Alameda County Study. Am J Public Health 2005;95:1595-601.

30. Cameron AJ, Spence AC, Laws R, et al. A review of the relationship between socioeconomic position and the early-life predictors of obesity. Curr Obes Rep 2015;4:350-62.

31. Bann D, Johnson W, Li L, et al. Socioeconomic inequalities in body mass index across adulthood: coordinated analyses of individual 
participant data from three British Birth Cohort Studies Initiated in 1946, 1958 and 1970. PLoS Med 2017;14:e1002214.

32. Jenum AK, Sletner L, Voldner N, et al. The STORK Groruddalen research programme: a population-based cohort study of gestational diabetes, physical activity, and obesity in pregnancy in a multiethnic population. Rationale, methods, study population, and participation rates. Scand J Public Health 2010;38(5 Suppl):60-70.

33. Bhopal RS. Migration, ethnicity, race, and health in multicultural societies. 2nd edn. Oxford, United Kingdom: Oxford University Press, 2014.

34. Sletner L, Jenum AK, Mørkrid K, et al. Maternal life course socioeconomic position and offspring body composition at birth in a multiethnic population. Paediatr Perinat Epidemiol 2014;28:445-54.

35. Sterne JA, White IR, Carlin JB, et al. Multiple imputation for missing data in epidemiological and clinical research: potential and pitfalls. BMJ 2009;338:b2393.

36. Headen I, Cohen AK, Mujahid M, et al. The accuracy of selfreported pregnancy-related weight: a systematic review. Obes Rev 2017;18:350-69.

37. Kumar BN, Holmboe-Ottesen G, Lien N, et al. Ethnic differences in body mass index and associated factors of adolescents from minorities in Oslo, Norway: a cross-sectional study. Public Health Nutr 2004;7:999-1008

38. Kumar BN, Meyer HE, Wandel M, et al. Ethnic differences in obesity among immigrants from developing countries, in Oslo, Norway. Int $J$ Obes 2006;30:684-90.

39. Rabanal KS, Lindman AS, Selmer RM, et al. Ethnic differences in risk factors and total risk of cardiovascular disease based on the Norwegian CONOR study. Eur J Prev Cardiol 2013;20:1013-21.

40. Skogberg N, Laatikainen T, Koskinen S, et al. Cardiovascular risk factors among Russian, Somali and Kurdish migrants in comparison with the general Finnish population. Eur J Public Health 2016;26:667-73.

41. WHO Expert Consultation. Appropriate body-mass index for Asian populations and its implications for policy and intervention strategies. Lancet 2004;363:157-63.

42. World Health Organization. Waist circumference and waist-to-hip ratio: report of a WHO expert consultation, Geneva. Geneva: WHO Document Production Services, 2008.

43. Berntsen S, Richardsen KR, Mørkrid K, et al. Objectively recorded physical activity in early pregnancy: a multiethnic population-based study. Scand J Med Sci Sports 2014;24:594-601.

44. Richardsen KR, Mdala I, Berntsen S, et al. Objectively recorded physical activity in pregnancy and postpartum in a multi-ethnic cohort: association with access to recreational areas in the neighbourhood. Int J Behav Nutr Phys Act 2016;13:1-12.

45. Sommer C, Sletner L, Jenum AK, et al. Ethnic differences in maternal dietary patterns are largely explained by socio-economic score and integration score: a population-based study. Food Nutr Res 2013;57:57

46. Baerug A, Sletner L, Laake P, et al. Recent gestational diabetes was associated with mothers stopping predominant breastfeeding earlier in a multi-ethnic population. Acta Paediatr 2018;107:1028-35.

47. Terragni L, Garnweidner LM, Pettersen KS, et al. Migration as a turning point in food habits: the early phase of dietary acculturation among women from South Asian, African, and Middle Eastern Countries living in Norway. Ecol Food Nutr 2014;53:273-91.

48. Telle-Hjellset V, Råberg Kjøllesdal MK, Bjørge B, et al. The InnvaDiab-DE-PLAN study: a randomised controlled trial with a culturally adapted education programme improved the risk profile for type 2 diabetes in Pakistani immigrant women. Br J Nutr 2013;109:529-38 